\title{
Non-destructive and precise studies of the growth of individual potato tubers (Solanum tuberosum L.) under field conditions.
}

\author{
Hammad N. Farhan ${ }^{1}$, G. Sagar ${ }^{2}$ and E.R.B. Oxley ${ }^{3}$ \\ ${ }^{1}$ Professor at Biology Department, College of Education for Pure Sciences, Al-Anbar \\ University, Iraq (E-mail: drhammad51@yahoo.com). \\ ${ }^{2}$ Professor at School of Biological Sciences, University of Wales, Bangor, U.K. \\ ${ }^{3}$ Assistant Professor at School of Biological Sciences, University of Wales, Bangor, U.K. \\ ABSTRACT
}

Non-destructive observations of growth of single tubers on individual potato plants (cv. Pentland Crown) grown in field revealed a great variation in total numbers of tubers per plant, total tuber volume per plant, volumes of individual tubers and growth behavior of each tuber. The largest tuber at any one time was not necessarily the largest at the next time. No relationship was found between the duration of the grand period of growth of tuber and its growth rate. Some tubers increased in volume, stopped and then resumed growth. Mixtures of Naphthalene Acetic Acid 45 mg/l (NAA) + 6-Benzyl Amino Purine $4.5 \mathrm{mg} / \mathrm{l}$ (BAP) had a dual effect by increasing tuber number and tuber size per plant when applied via the leaves in different times. The mixture of NAA + BAP increased tuber number per plant at pre-tuberization by $39.1 \%$ and at-tuberization by $13.1 \%$ and decreased the number by $21.9 \%$ at post-tuberization stage compared with control. The mean number of tubers per plant in pre-tuberization treatment was greater than that in at- and posttuberization treatments by $27 \% \& 47 \%$ respectively. The percentage increase in total volume of tuber per plant (yield) compared with control treatments were $14.8 \%, 39.5 \%$ and $13.8 \%$ respectively. It is concluded that the application time with mixture of NAA + BAP to potato plants at-tuberization stage was the best to increase tubers yield.

Keywords: Growth rate of tuber, Behavior of tuber, Non-destructive observations, NAA, BAP

\section{INTRODUCTION}

It has been reported that there is a great variation in the total number and the size of tubers per potato plant (Wurr, 1977; Ahmed \& Sagar, 1981b). Many workers have also reported that the size of individual tubers on a single potato plant varies to a great extent on the time of harvest (i.e. Clark, 1921; Krijthe, 1955; Hewitson, 1967; Moorby, 1967, 1968; Gray, 1973; Wurr, 1977; Ahmed \& Sagar 1981b, Engels \& Marschner, 1986 a, b, c; and Struik et al., 1988). For instance, Clark (1921) and Ahmed \& Sagar (1981b) showed that both the duration of the main period of growth and growth rates vary and act independently to determine the final size of each tuber. Krijthe (1955) assumed that the first formed tuber within a hill was always the largest; the differences in tuber size within a hill were dependent on the spread of time of tuber formation. Moorby (1968) has deduced from results of ${ }^{14} \mathrm{C}$ tracer studies that individual tubers showed different rates of growth relative to each other such that the largest at one harvest may not necessarily be the largest at a sequent harvest. Plaisted (1957) reported a logarithmic relationship between mean tuber weight and time. Moorby and Milthorpe (1975) concluded that the rate of growth of total tuber volume per plant (the rate of bulking) is exponential for the first two to three weeks but then becomes almost linear. Similarly, Gray (1973) showed that tubers grew linearly over their early stages and assumed that the largest tuber at the time of initial measurements was the first to be initiated. Moreover, Wurr (1977), from measurements of the growth of individual tubers, showed that some tubers followed an approximately sigmoid curve, some grew linearly and some showed periods of growth interrupted by periods when the tubers grew slowly, if at all. Further, he added that the time over which tuber formation occurred was not important. Strunik et al., (1999) reported that tuber formation is a plastic and complex with physiological and genetic control are involving in tuber formation.

Growth of the tuber is primarily the results of cell division and subsequent cell enlargement of the stolon tips (Artschwager, 1924; Reev, Tim \& Weaver, 1973a). Oparka (1985) showed no relationship between the node of origin of a tuber and the amount of ${ }^{14} \mathrm{C}$ which entered it.

Many reports have argued the involvement of several growth regulating substances in tuberization and in 
tuber development (e.g., Van Staden \& Dimalla, 1976, 1977; Ahmed \& Sagar, 1981a; Melis \& Van Staden, 1984; and Ahmad et al., 1999).

In vitro, many studies have confirmed the success about the effect of Plant Growth Regulators (PGRs) on callus induction and plant regeneration in culture of potato (Esna-Ashari \& Villers, 1998; Nowak et al., 1999; Khatun et al., 2003; Yasmin et al., 2003; Hossain et al., 2006; Shirin et al, 2007). The explants of potato plant cultured on Murashige \& Skoog (1962) medium (MS) without growth regulator did not produce any callus (Abd Elaleem et al., 2009). While, Shirin et al., (2007) found that 2,4-D at $3 \mathrm{mg} / \mathrm{l}$ as an auxin most effective for callus induction in four potato cultivars compared with other growth regulators. Abd Elaleem et al., (2009) obtained the best degree for callus formation from tuber segments as an explants cultured on MS medium supplemented with 2,4-D at $3 \mathrm{mg} / \mathrm{l}$ or 2,4-D in combination with BA both at $2 \mathrm{mg} / \mathrm{l}$. Dragicevic et al., (2008) found that potato shoots grown in vitro in continuous darkness or in long days (LDs) that IAA alone stimulated stolon formation in LDs, both in presence or absence of $\mathrm{GA}_{3}$, and stimulated tuber formation in dark-grown shoots, but could not overcome the inhibitory effect of LDs.

Shoots, roots and callus were formed from tuber discs of potato, cultivar Desiree, when grown in vitro on the basal medium of MS supplemented with 2,4-D $(0.5 \mathrm{mg} / \mathrm{l})$ and/or BAP (1 mg/l) (Esna-Ashari \& Villers, 1998).

Many workers succeeded on the induction of micro tubers on MS medium using different Plant Growth Regulators (PGRs) (Rosell et al., 1987; Nowak et al., 1999). Rosell et al., (1987) found mass production was obtained on plantlets growing from nodal potato cuttings cultured in vitro on MS medium under continuous light of $5000 \mathrm{Lux}$ at $24-25{ }^{\circ} \mathrm{C}$.

Many researchers have successfully studied the effect of exogenous application of PGRs on potato yield grown under field or laboratory conditions (Okazawa, 1960; Krauss \& Marschner, 1976; and Ahmed \& Sagar, 1981a). Caldiz et al., (1998) used many different PGRs like BAP, GA3, and BAP + GA3 in two experiments with two potato cultivars; they found those sprayed with BAP maintained ground cover and photosynthesis for longer and those sprayed with $\mathrm{GA}_{3}$ for a shorter period. Ahmad et al., (1999) concluded that potato plants responded well to the L- Tryptophan concentrations of $10^{-5}$ and $10^{-6}$ $M$ respectively in increasing tuber yield compared with control plants. Similar results were found by
Dragicevic et al., (2008), they found in potato shoot cultures in vitro that IAA alone stimulated tuber formation in dark-grown shoots.

Therefore, from these conclusions more work is needed to understand the behavior of individual tuber per potato plant. This research examines the effects of mixture of NAA + BAP treatments when applying in different times on the growth of individual tubers using a non-destructive method of tuber volume measurement compared with control plants under field conditions.

\section{MATERIALS AND METHODS}

Big job has been done by using sixty individual plants distributed into six treatments under field conditions as the following: 80 chitted tubers of potato cv. Pentland Crown each of 50-60 g fresh weight and from which all buds removed, except the apical buds were planted separately $10 \mathrm{~cm}$ deep in sand in pots of $20.3 \mathrm{~cm}$ diameter. Pots were placed in greenhouse, the minimum temperatures were $15^{\circ} \mathrm{C}$ (day) and $10^{\circ} \mathrm{C}$ (night) and the relative humidity was maintained between $60 \%$ to $70 \%$.

63 days after planting, 60 uniform plants with single shoots (13-18 cm high) were transferred to special growth units. These plants were at the stolon initiation stage. These units were plastic pots $28 \mathrm{~cm}$ in diameter, the base (bottom) of which had been cut at height of $11 \mathrm{~cm}$ the bases of these rings were then closed with a thick polythene sheet which had a circular hole $\left(1 \mathrm{~cm}^{2}\right)$ in the center. Each plant was placed in a pit which had been prepared in the ridges of the potato field at the Pen-y-ffridd experimental station, Bangor, Gwynedd, U.k. The tops of the rings were at the soil level. The mother tuber was gently detached from the selected plants and the roots were passed through the hole in the polythene sheet and buried in the soft wet soil of the pit. The upper chamber was filed with dry sand which was covered with non-absorbent cotton wool. Hard board $(30 \mathrm{~cm} \mathrm{x}$ $15 \mathrm{~cm}$ ) covered with polythene sheet was secured onto the top of the rings to protect the dry sand from rain. Each board contained a notch in the middle to allow the shoots to pass through the cover without damage (Fig. 1). The system was similar to that used by Ahmed (1978). Tubers were subsequently identified by using plastic covered rings in different colors which were secured onto the stolons (Fig.1). In this experiment, for convenience tubers were identified from the largest to the smallest referred to as $1,2,3,4$, etc. the sixty units were planted in four ridges in the middle of the potato field $(75 \mathrm{~cm} \times 50 \mathrm{~cm}$ ) and distributed for six treatments in completely 
random design (CRD) (Table 1). One week after transplanting the foliage of the ten plants of treatment T1 were selected and sprayed with distilled water while the ten plants of treatment T2 were selected and their foliage sprayed with a mixture of NAA $45 \mathrm{mg} / \mathrm{l}+\mathrm{BAP} 4.5 \mathrm{mg} / \mathrm{l}$ at the pre tuberization stage. Tween $20(0.01 \%)$ was used in both solutions as a wetting agent. Four weeks after transplanting, a similar treatment was given to separate plants at the tuberization stage (T3 \& T4) and on eight weeks after transplanting, another was carried out on plants posttuberization ( $T 5 \&$ \& 6 ). Each plant was sprayed individually gently with $50 \mathrm{~cm}^{3}$ of the appropriate solution using a Hill All Purpose Hand Spray No. 34.

Measurements of individual tubers were made carefully in four times: $6,11,13$ and 17 weeks after transplanting. Dividers were used to measure the length and diameter of each tuber and volume was calculated by: $v=\left(a b^{2} \#\right) / 6$ where $v=$ volume, $a=$ length of tuber, $a=$ diameter of tuber (Hewitson, 1967; Gray, 1973; Ahmed, 1978; Parka \& Davies, 1985). At each of reading a domestic vacuum cleaner was used to extract the dry sand which was replaced after the appropriate observations had been made. An electric generator was used to generate the power for this purpose. The operations of each measurement were done over a period of two days. On 17 weeks after transplanting all the plants were harvested separately and the final volume of each labeled tuber was measured.

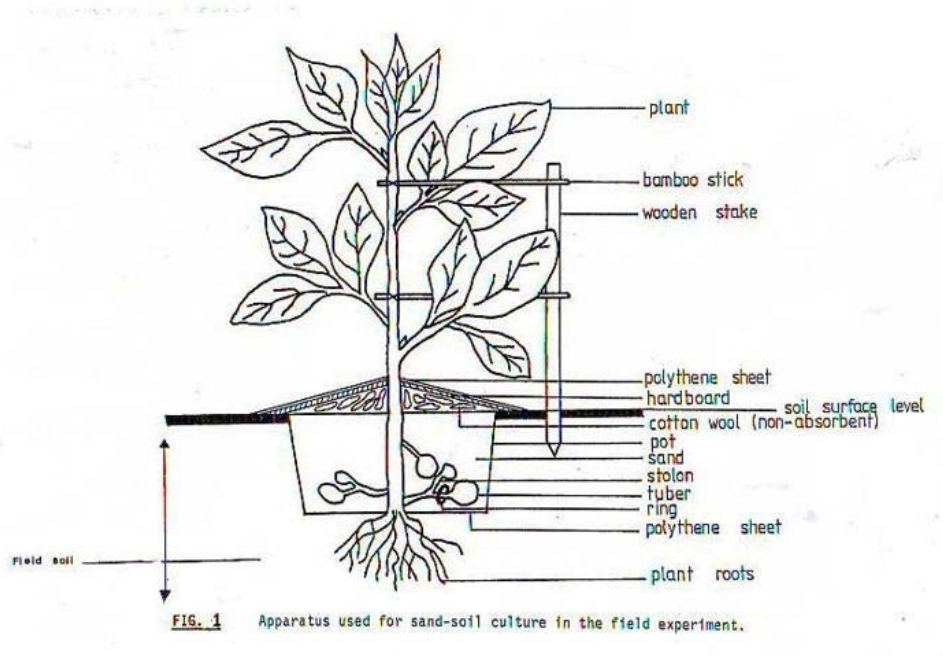

\section{RESULTS:}

All the plants in each treatment were fully tuberized six weeks after transfer onto the observation pots, and all survived until harvest time. Tuber number per plant ranged from 3 (plant 10) to 16 (plant 7) in treatment T1, from 6 (plant 1, 7) to 36 (plant 5) in T2, from 4 (plant 3,5 ) to 13 (plant 2) in T3, from 4 (plant 10) to 40 (plant 5) in T4, from 6 (plants 3,10 ) to 21 (plant 5) in T5 and from 3 (plants 6,7) to 19 (plant 1) in T6. In general, spraying with the mixture of NAA + BAP increased tuber number per plant when applied pre and at tuberization stage compared with posttuberization and control treatments. The mean number of tubers per plant in treatment T2 (pretuberization) was greater than that in $\mathrm{T} 4$ (at tuberization) and T6 (post tuberization) by $27 \% \& 47$
$\%$ respectively (Tables $2 \& 3$ ). The percentage increase in total volume of tuber per plant (yield) compared with control treatments were $14.8 \%, 39.5$ $\%$ and $13.8 \%$ respectively.

In general, at harvest time there were no significant differences between treatments at p 0.05 in all parameters. However, the analysis of percentages and standard deviation (SD) showed clear differences between treatments (Table 2).

It is concluded that the application time with mixture of NAA + BAP to potato plants at-tuberization stage was the best to increase tubers yield.

Mean Volume: The post tuberization treatment T6 produced the highest mean volume per tuber per plant $\left(268.5 \mathrm{~cm}^{3}\right)$ and for treatment T4 it was $(242.9$ 
cm3). Similar results were obtained for the mean volume of tuber per plant for treatments T1, T2, T3 and T5 (Table 2).

At the harvest time, the mean total volume of tubers per plant in treatment T4 was greater than that in treatment T6 or T2. The percentage increase in yield (total volume/plant) compared with the control treatments were $14.8 \%$ in T2 $39.5 \%$ in T4 and 13.8 $\%$ in T6 (Table 2). Data indicate that the response of the individual tuber per plant to PGRs in T6 (treated at post-tuberization) was higher than in T4 (treated at tuberization) and T2 (treated at pre-tuberization), and indicate dependence on time of application. In control treatments, T1 and T3 were very similar in the mean volume per tuber, but it was greater than the mean volume of treatment $\mathrm{T} 5$.

The growth of individual tubers in each treatment:

a) Pre-tuberization treatments: Plant no 10 was selected to represent the 10 plants in the control treatment (T1) and plant 1 was selected to represent the 10 plants that received plant regulators treatment (T2).

On the control plant (Fig. 2) all the tubers grew normally during the recorded period, tubers T1 \& T2 showed sigmoid curve while tuber T3 showed linear course, and tuber T2 scored the highest volume at harvest time $\left(450 \mathrm{~cm}^{3}\right)$. By contrast, four tubers in plant 1 (Fig. 3) which were sprayed with PGRs showed greater growth rates after week 6 until the end of experiment. Tubers T1, T3 \& T4 showed sigmoid curve and tubers T2, T5 \& T6 showed linear course after application with hormones. Tubers T3 \& T5 scored higher volume than tubers T2 \& T4 at harvest time. While tuber T1 scored the highest volume at final record $\left(455 \mathrm{~cm}^{3}\right)$.

b) At tuberization treatment: Plant 3 was selected to represent control treatment (T3), and plant 7 was selected to represent PGRs treatment (T4). On the control plant (Fig. 4) most tubers developed normally from the time of first recording to the end of the experiment. Most tubers showed linear course and one showed sigmoid course in their growth. Tuber T2 scored higher volume than tuber T3 at final record. Tuber T1 scored the highest volume at harvest time (about $500 \mathrm{~cm}^{3}$ ). In contrast, all tubers on plant 7 (treated with PGRs) showed higher growth rate after the treatment which carried out before week six (Fig. 5 ). Most tubers showed linear course in their growth. Tuber T2 scored the highest volume at the final record $\left(610 \mathrm{~cm}^{3}\right)$. However, after week 11 one new tuber was initiated on plant 7 .

c) Post-tuberization treatment: Plant 10 was selected to represent the control treatment (T5), and plant 6 was selected to represent PGRs treatment (T6). Control plant (Fig. 6) most tubers developed slowly and no marked effect was observed on the growth of the tubers of plant 10 which had been treated with distilled water. However, Some tubers showed linear course (e.g. tubers T1 \& T2) and some showed sigmoid course in their growth (tubers T3 \& T4). Tuber T1 was the largest at the first recording, was also the largest at harvest (about $325 \mathrm{~cm}^{3}$ ). Tuber T3 was larger at the first recording than tuber T4 but in the $2^{\text {nd }}, 3^{\text {rd }}$ and final recording tuber T4 scored higher growth rate than tuber T3. In contrast, all tubers on plant 6 (treated with PGRs) showed higher growth rate after the treatment and showed increased growth during the treatment period, and tuber T1 recorded the highest volume (more than 850 $\mathrm{cm} 3$ ). Tuber T3 scored the second value at harvest time. While tuber T2 scored third value at final record $\left(570 \mathrm{~cm}^{3}\right)$. There was no inhibition for the tuber growth following application of PGRs to all the treated plants in this treatment (Fig.7).

Usually, PGRs treated plants had higher volumes per tuber than those on untreated plants. Plants treated with mixture of NAA + BAP at post-tuberization had fewer small tubers than plants which treated pre- or at tuberization. Treatment T6 produced larger tubers than treatments T2 \& T4. 
Agric. Biol. J. N. Am., 2010, 1(3): 296-306

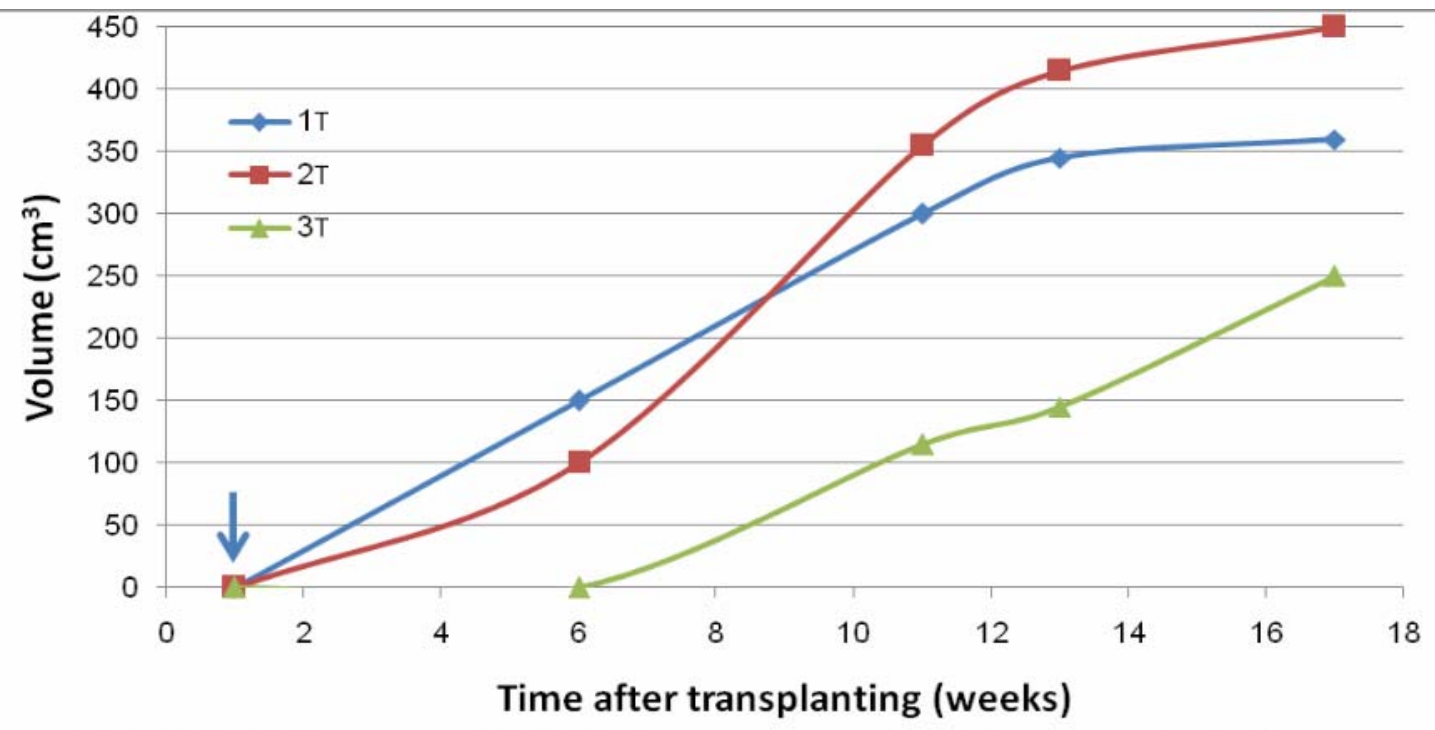

Fig (2) Effect of spraying with distilled water on growth of tubers pre tuberization $\downarrow=$ Time of application pre -tuberization

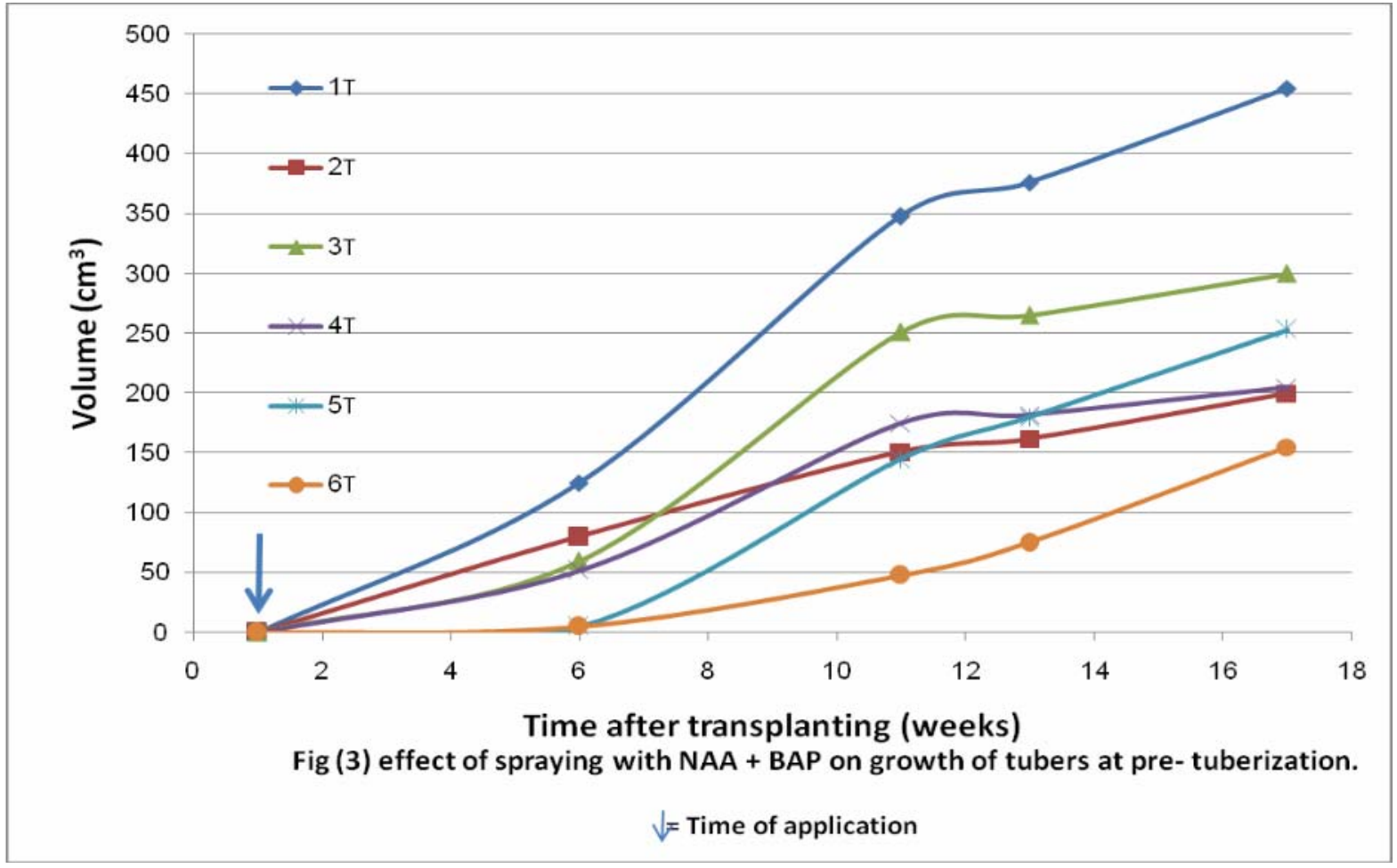


Agric. Biol. J. N. Am., 2010, 1(3): 296-306
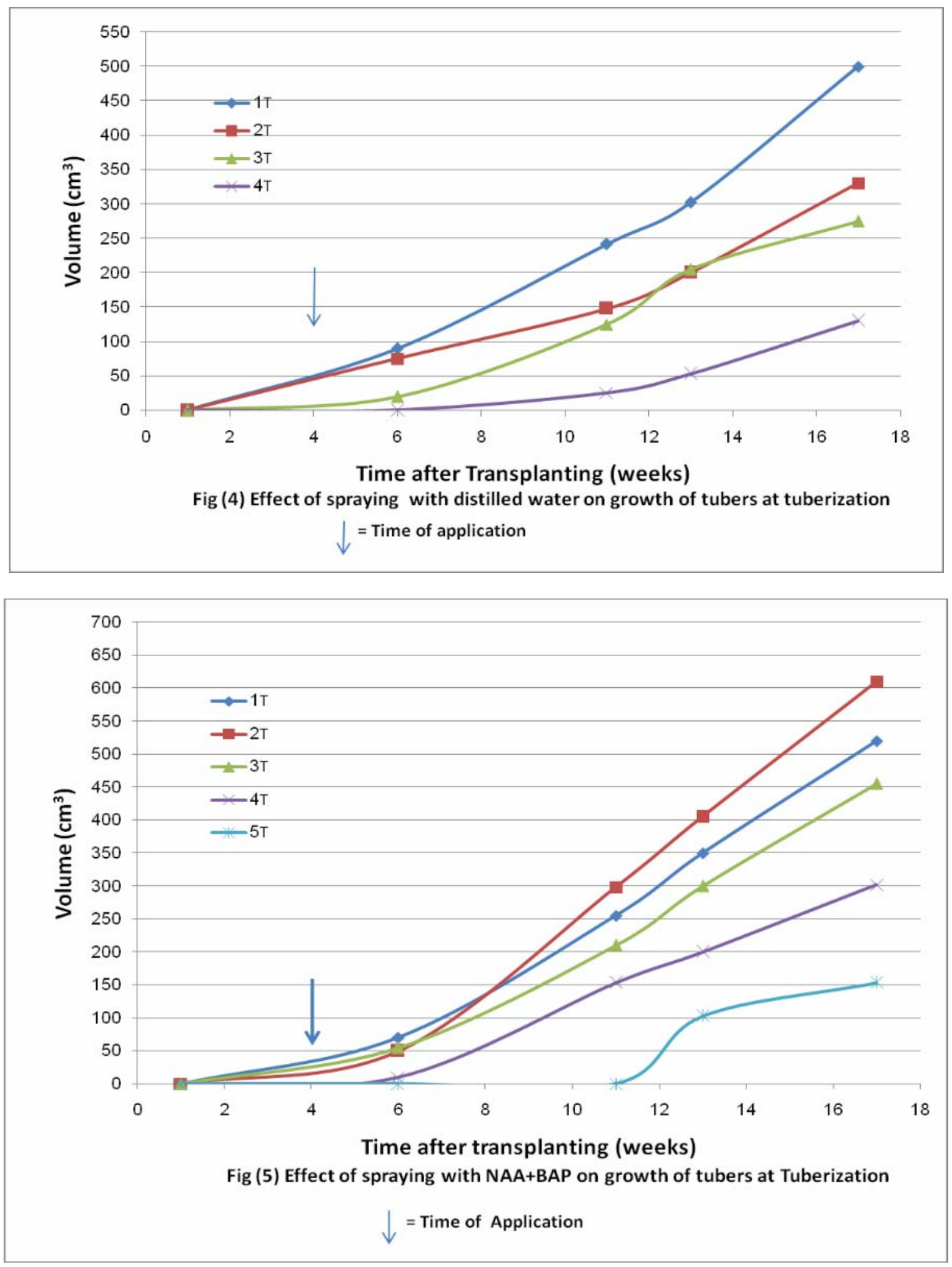
Agric. Biol. J. N. Am., 2010, 1(3): 296-306
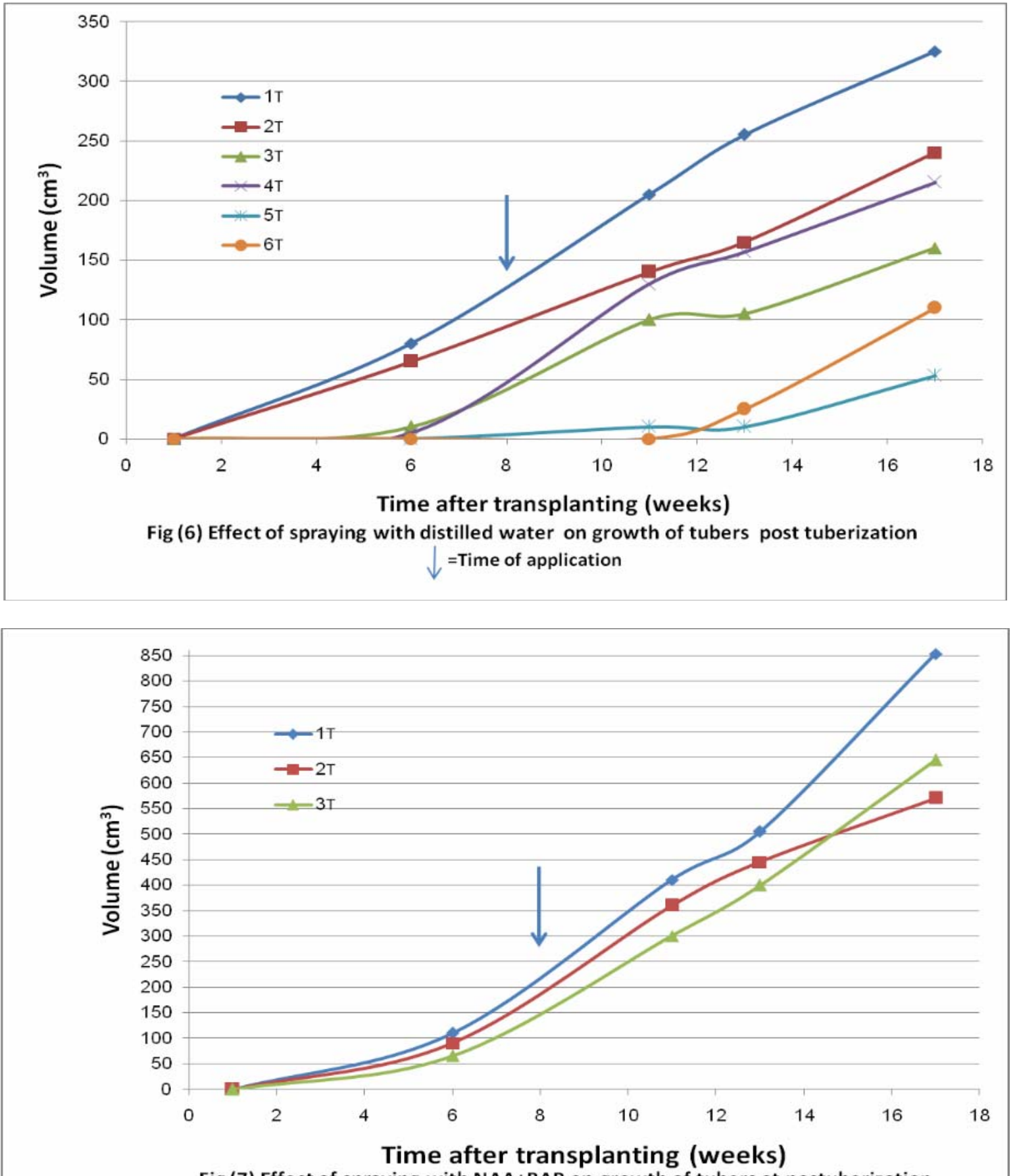

Fig (7) Effect of spraying with NAA+BAP on growth of tubers at postuberization

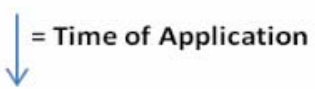




\section{DISCUSSION}

First of all it is better to discuss the behavior of the individual tubers on control plants in treatments $\mathrm{T} 1$, T3 and T5.

Observations of growth of each tuber on individual plants grown under field and greenhouse conditions revealed a very high variation in tuber number, tuber volume and growth rate of tubers. All the plants were from same variety: every mother tuber was similar to others in size, chitted in the same conditions, planted in the same greenhouse and transplanted into the same field in similar units on the same day. Theoretically, it can be presumed that tuber production in each plant/treatment should be relatively uniform. In reality, however, it was not. Every plant in each treatment contained very large variation between tubers, whether in number, size or in the behavior of their growth.

The individual tubers on field grown plants showed different courses of growth patterns at different times. For example, tuber (T3) on Fig. 2 and tuber (T1) on Fig. 4 followed a linear course, this agree with (Gray, 1973) who showed that tubers grew linearly over their early stages and assumed that the largest tuber at the time of initial measurements was the first to be initiated, tubers (T1) and (T2) on Fig.2 and tubers (T3) \& (T4) on Fig. 6 followed sigmoid course, and tuber (T5) on Fig. 6 followed a slow course: some times, tubers which stopped growth resumed growth again as with tuber (T5) on Fig. 6. Similar results have been reported by Wurr (1977) who showed that some tubers followed an approximately sigmoid curve, some grew linearly and some showed periods of growth interrupted by periods when the tubers grew slowly, if at all. It is obvious from these observations that the time over which tuber formation occurred was not important, this agrees with Wurr (1977).

The results from the present study do support the suggestion by Moorby (1968) that the individual tubers of a plant show different rates of growth relative to each other, such that the largest tuber at any time need not necessarily be the largest on any future occasion.

It is difficult to determine one factor is behind tuber formation and tuber growth. Various factors are affecting tuber formation and tuber growth like environment (Burt, 1964; Ahmed, 1978), interaction between endogenous hormones (Kumar \& Wareing, 1974), exogenous hormones, Dragicevic et al.,
(2008), found in potato shoot cultures in vitro that IAA alone stimulated tuber formation in dark-grown shoots. While, Strunik et al., (1999) reported that tuber formation is a plastic and complex with physiological and genetic control are involving in tuber formation.

Furthermore, Krijthe (1955) assumed that tuber formation is generally completed within two or three weeks, so the number of tubers present on week 3 after initiation is never exceeded later. However, these conclusions are in disagreement with some of the results as some tubers were initiated even after week 3 (e.g., Fig. 6).

It is difficult to regulate tuber formation or tuber growth by addition PGRs. But from our results in this study, it is evident that the large tubers were more responsive to the mixture of NAA + BAP than the small tubers, which may be related to the high level of endogenous hormones in small tubers. With external PGRs these endogenous ones, suppression of growth takes place: the higher the concentration of PGRs applied, the greater the reduction in growth. Van Staden \& Dimalla (1977) found that the stolon tips and the smallest little tubers contained higher levels of at low concentration cytokinins than the large tubers. Similar results have been reported by Wurr et al., (1980). It seems reasonable to suggest that in general, direct application of PGRs as an auxin and cytokinins via plant leaves accelerated the volume increase of tubers at post-tuberization stage much better than at pre and at tuberization stages. This agree with Esna-Ashari \& Villiers (1998), who found that shoots, roots and callus were formed from tuber discs of potato, cultivar Desiree, when grown in vitro on the basal medium of (MS) supplemented with 2, 4-D and BAP.

Total volume of tubers per plant was increased by $40 \%$ by hormones supplied at the tuberization stage. Meanwhile, application at the pre-tuberization stage also increased the number of tubers per treatment by $39 \%$ as compared to the control treatment. Theoretically, it may be said that the mixture of auxin and cytokinin (NAA +BAP) in this study may have increased cell division and cell size of the stolon tips directly (tuberization) or modified the level of endogenous growth substances indirectly. Any increase in sink (i.e. tuber number per plant) will tend to reduce the individual tuber growth rate unless more assimilates are transported to the tubers (Laycock, 1971). 
Despite the high variation, it is evident from the present results that mixture of NAA + BAP had a dual effect of increasing tuber number and tuber size per plant when applied via the leaves. In most cases, if the field study is repeated on a larger scale with similar technique and with more cultivars, and the results are confirmed it may then be possible to suggest that carefully timed spraying of the tested mixture may be used to control the time of tuberization, tuber size or number of tubers per plant.

\section{CONCLUSIONS:}

The mode action of PGRs when applied exogenously, either have direct action to increase cell division and cell enlargement of stolon tips and tubers, or they have indirect action by activating the endogenous hormones.

Application with PGRs to potato plants were found much helpful to increase potato yield when they spray in the right concentration, in the right way, at the best time and at the best age of plant. Use PGRs in agriculture are much cheaper and easier technique comparing with the traditional methods of fertilizer application.

No doubt further work is required to ascertain whether this mixture has an effect on the endogenous ratio of promoting/inhibiting hormones in the potato plants.

Table 1. The basic design of field experiment.

\begin{tabular}{lccc}
\hline Treatments & NAA + BAP $(\mathrm{mg} / \mathrm{l})$ & Time of application & Date of treatment \\
\hline T1 & $0+0$ & pre-tuberization & one week after tuberization \\
T2 & $45+4.5$ & $===$ & $==$ \\
T3 & $0+0$ & at tuberization & four weeks after tuberization \\
T4 & $45+4.5$ & $===$ & $==$ \\
T5 & $0+0$ & post-tuberization & eight weeks after tuberization \\
T6 & $45+4.5$ & $===$ & $==$ \\
\hline
\end{tabular}

Table 2. some parameters at final harvest of plants grown in the field. Mean of 10 plants in each treatment.

\begin{tabular}{lccccc}
\hline Treatments & $\begin{array}{c}\text { Total no. of } \\
\text { Tuber per tre- } \\
\text { atment }\end{array}$ & $\begin{array}{c}\text { Mean No of } \\
\text { tubers/plant }\end{array}$ & $\begin{array}{c}\text { Mean volume } \\
\text { per tuber at } \\
\text { harvest }\left(\mathrm{cm}^{3}\right)\end{array}$ & $\begin{array}{c}\text { mean Total volume } \\
\text { of tubers/plant } \mathrm{cm}^{3}\end{array}$ & $\begin{array}{c}\text { \% increase } \\
\text { in volume }\end{array}$ \\
\hline T1 & 87 & 8.7 & 195.8 & 1703.5 & 100.0 \\
T2 & 121 & 12.1 & 161.6 & 1955.4 & 114.8 \\
T3 & 84 & 8.4 & 196.9 & 1654.0 & 100.0 \\
T4 & 95 & 9.5 & 242.9 & 2307.6 & 139.5 \\
T5 & 105 & 10.5 & 184.3 & 1935.2 & 100.0 \\
T6 & 82 & 8.2 & 268.5 & 2201.7 & 113.8 \\
\hline SD & 15 & 1.5 & 39.7 & 260.5 & --
\end{tabular}

Table 3. Final total of tubers on each plant grown in the field after treatment with mixture of NAA + BAP at different times.

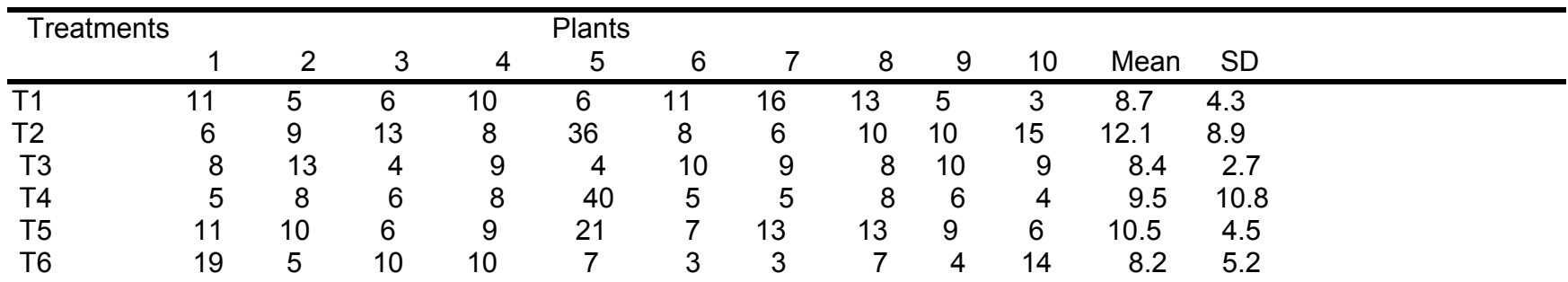

\section{REFERENCES}

Abd Elaleem, K.G., Modawi, R.S. and Khalafalla, M.M. (2009). Effect of plant growth regulators on callus induction and plant regeneration in tuber segment culture of potato (Solanum tuberosum L.) cultivar Diamant. African J. of Biotechnology, 8(11), 2529-2534
Ahmad, M., Pervez, M.A., Tahir, F.M. and Anwar-Ul-Haq (1999). effect of L- Tryptophan on the growth and yield of potato cv. Pars-70. Int. J. Agriculture and Biology, 1(2), 3032

Ahmed, CH. M. S (1978). Tuber growth in Solanum tuberosum. Ph.D. Thesis, University of Wales, U. K. 
Ahmed, CH. M. S. and Sagar, G. R. (1981a). Effects of mixture of NAA + BAP on number and growth of tubers of Solanum tuberosum L. Potato Research, 24, 267-278

Ahmed, CH. M. S. and Sagar, G. R. (1981b). volume increase of individual tubers of potatoes grown under field conditions. Potato Research, 24, 269-288

Caldiz, D.O., Clua, A., Beltrano, J. and Tenenbaum, S.D. (1998). Ground cover, photosynthetic rate and tuber yield of potato (Solanum tuberosum L.) crops from seed tubers with different physiological age modified by foliar applications of plant growth regulators. Potato Research, 41(2), 175-185

Clark, C. F. (1921). Development of tubers in the potato. Bulletin No. 958, United States, Department of Agriculture.

Dragicevic, I., Konjevic, R., Vinterhalter, B., Vinterhalter, D. and Neskovic, M. (2008). The effects of IAA and tetcyclacis on tuberization in potato (Solanum tuberosum L.) shoot cultures in vitro. Plant Growth Regulation, 54(3), 189-193

Ehsanpour, AA. and Jones, MGR. (2000). Evaluation of direct shoot regeneration from stem explants of potato (Solanum tuberosum L.) cv. Deaware by thidazuron TDZ. J. Sci. Tech. Agric. Natl. Res., 4, 47-54

Engels, CH. And Marschner, H. (1986a). allocation of photosynthate to individual tubers of Solanum tuberosum L. Journal of Experimental Botany, 37, 1795-1803

Engels, CH. And Marschner, H. (1986b). allocation of photosynthate to individual tubers of Solanum tuberosum $L$. II relation between growth rate, carbohydrate concentration and $14 \mathrm{C}$ partitioning within tubers. Journal of Experimental Botany,37, 1804-1812

Engels, CH. And Marschner, H. (1986c). allocation of photosynthate to individual tubers of Solanum tuberosum $L$. relation between growth rate of individual tubers, tuber weight and stolon growth prior tuber initiation. Journal of Experimental Botany, 37, 1813-1822

Esna-Ashari, M. and Villiers, T.A. (1998). Plant regeneration from tuber discs of potatoes (Solanum Tuberosum L.) using 6-benzylaminopurine (BAP)> Potato Research, 41(4), 371-382

Gray, D. (1973). The growth of individual tubers. Potato Research, 16, 80-84

Hewitson, J. F. (1967). Translocation in the potato with special references to variation in tuber size. Ph. D. Thesis, University of Wales, U. K.

Hossain, I. Chaudhry, Z., Muhammed, A., Asghar, R., Naqvi, S.M.S. and Rashid, H. (2006). Effect of chlorocholine chloride, sucrose and BAP on in vitro tuberization in potato (Solanum tuberosum L.) cV. Cardinal. Pak. J. Bot., 38(2), 275-282

Khatun, N., Bari, MA., Islam, R., Huda, S., Siddque, NA. Rahman, MA. And Mullah, MU. (2003). Callus induction and regeneration from nodal segment of potato cultivar Diamant. J. Biol. Sci., 3, 1101-1106

Krauss, A. and Marshner, H. (1976). Influence of nitrogen nutrition and application of growth regulators on tuber initiation in potato plants. Z. pflanzenernahrung und Budenkunde, 139(2), 143-155

Krijthe, N. (1955). Observations on the formation and growth of tubers on the potato plant. Netherlands Journal of Agricultural science, 3, 291-304

Kumar, D. and Wareing, P. F. (1974). Studies on tuberization of Solonum andigena. II. Growth hormones and tuberization. New Phytologist, 73, 833-840

Laycock, D. (1971). Modification of potato tuberby Ndimethylamino succinamic acid. Potato Research, 14, 234236

Melis, R. J. M. and Van Staden, J. (1984). Tuberization and hormones. Z. pflanzenernahrung und Budenkunde, 113, 271-283

Moorby, J. (1967). Inter-stem and Inter-tuber competition in potatoes. European Potato Journal, 10(3), 189-205

Moorby, J. (1968). The influence of carbohydrate and mineral nutrient supply on the growth of potato tubers. Annals of Botany, 34, 279-308

Moorby, J. and Milthorpe, F. L. (1975). Potato in: Crop Physiology, some cases histories, ed. Evans, L. T. pp. 225257, Cambridge University Press.

Murashige, T. and Skoog, F. (1962). A revised medium for rapid growth and bioassays with tobacco tissue culture. Physiol. Plant., 15, 473-497

Nowak, J., Bensalim, S., Smith, C.D., Dunbar, C., Asiedu, S.K., Madini, A., Lazarovits, G., Northcott, D. and Sturz. A.V. (1999). Behavior of plant material issued from in vitro tuberization. Potato Research, 42, 505-519

Okazawa, Y. (1960). Studies on the relation between the tuber formation of potato and its natural gibberellins content. Proc. Crop. Sci. Soc., Japan, 29, 121-124

Oparka, K. J. (1985). Changes in partitioning of current assimilates during tuber bulking in potato (Solanum tuberosum L.) cv. Maris Piper. Annals of Botany, 55, 705713

Oparka, K. J Davis, H. V. (1985). Translocation of assimilates within and between potato stems. Annals of Botany, 56, 45-54

Plaisted, P. H. (1957). Growth of the potato tuber. Plant Physiology, 32, 445-453

Reeve, R. M., Timm, H. and Weaver, M. L. (1973a). parenchyma cell growth in potato tubers. 1. Different tubers regions. American Potato Journal, 50, 49-57 
Agric. Biol. J. N. Am., 2010, 1(3): 296-306

Rosell, G., De Bertodi, F.G. and Tizio, R. (1987). In vitro mass tuberization mass tuberization as a contribution to potato micro propagation. Potato Research, 30(1), 111-116

Shirin, F., Hossain, M., Kabir, MF., Roy, M. and Sarker, SR. (2007) Callus induction and plant regeneration from intermodal and leaf explants of four potato (Solanum tuberosum L.) cultivars. World J. Agric. Sci., 3(1), 1-6

Struik, P. C., Schniders, B. J., Kerchoffs, L.H.J. and Visscher, G.W.J. (1988). A device for measuring the growth of individual tubers non-destructively and precisely. Potato Research, 31, 137-143

Struik, P. C., Vreugdenhil. D., Van Eck, H. J., Bachem, C.W. and Visser, R.G.F. (1999). Physiological and genetic control of tuber formation. Potato Research, 42(2), 313-331

Van Staden, J. and Dimalla, G.G. (1976). Cytokinins from soils. Planta, 130 , 85-87
Van The distribution of cytokinins in tuberizing potatoes. Staden, J. and Dimalla, G.G. (1977)

Annals of Botany, 41, 741-746

Wurr, D.C.E. (1977). Some observations of patterns of tuber formation and growth in potato. Potato Research, 20, 63-75

Wurr, D. C.E. Akehurst, J.M. and Thomas, T. H. (1980). A comparison of gibberellins and cytokinins level in normal and little potato tubers. Potato Research, 23, 243-247

Yasmin, S., Nasiruddin, KM., Begum, R., Talukder, SK. (2003). Regeneration and establishment of potato plantlets through callus formation with BAP and NAA. Asian J. Plant 2(12), 936-940 